\title{
The Effect of Intravenous Magnesium Therapy on Spinalanaesthesia Produced by Bupivacaine In Pre-Eclamptic Patients
}

\author{
Sanjeev Kumar ${ }^{1}$, Chandrakant Prasad $^{2}$, Sandeep Sharan ${ }^{3}$, \\ Soma Bhattacharya ${ }^{4}$, Ajit Gupta ${ }^{5}$, Neha Singh ${ }^{6}$ \\ ${ }^{1}$ Additional Professor, Department Of Anaesthesiology\&Critical Care Medicine, I.G.I.M.S, Patna, \\ Bihar, India) \\ 2,3,4,6 (Junior Resident, Department Of Anaesthesiology\&Critical Care Medicine, I.G.I.M.S, Patna, \\ Bihar, India) \\ 5 ( ProfessorAnd Head, Department Of Anaesthesiology\&Critical Care Medicine, I.G.I.M.S, Patna, \\ Bihar, India)
}

\section{Corresponding Author:}

Dr. Chandrakant Prasad

Department of Anaesthesiology\& Critical Care Medicine

Indira Gandhi Instituteof Medical Sciences, Patna

E-mail: chandrakant.rims07@gmail.com

Phone: 9572598662

\begin{abstract}
Background:Magnesium has anti-nociceptive effects and potentiates opioid analgesia following its systemic and neuraxial administration. In our study, the effect of intravenous magnesium sulphate in pre-eclamptic patients on spinal anaesthesia produced by bupivacaine was investigated.

Materials and Methods:Sixty pregnant (30 normal and 30 pre-eclamptic) patients were enrolled in this study in two groups: Healthy parturients (Group A) and pre-eclampticparturients with IV MgSO4 therapy (Group B). Spinalanaesthesia was given with $12.5 \mathrm{mg}$ hyperbaric bupivacaine .Onset of sensory block at T6 level, highest sensory block level, motor block characteristics, time to first analgesic request, maternal hemodynamics as well as side effects were evaluated.

Results:Sensory block onset time at T6 was significantly more in group A than group B. Time to first postoperative analgesic request was significantly prolonged in Group B than in Group A. Side effects were similar in both groups.

Conclusion: Treatment with $\mathrm{IV} \mathrm{MgSO}_{4}$ in pre-eclampticparturients significantly prolonged the time to first analgesic request compared to healthy parturients.
\end{abstract}

Keywords: Spinal anaesthesia, magnesium sulphate, bupivacaine, pre-eclampsia

\section{Introduction}

Preeclampsia is a hypertensive disorder of pregnancy characterisedby triad of hypertension, proteinuria and generalized oedema. Management of pregnant patient with pre-eclampsiaposses great anaesthetic difficulties. Magnesium is an essential part of therapy in preeclampsia for eclampsia prophylaxis. Besides its anticonvulsant and neuroprotective properties, this bivalent cation is an N-methyl-D-aspartate (NMDA) receptor antagonist and is frequently described in the anaesthesia literature for its anti-nociceptive properties. ${ }^{1,2}$ Several studies have been done in non-obstetric populations which reported intravenous (IV) magnesium administration to be beneficial for postoperative analgesia following neuraxialanaesthesia ${ }^{3-6}$, whereas one study could not demonstrate this effect ${ }^{7}$. This controversy can be justified by the fact that, in healthy humans, the passage of magnesium to cerebrospinal fluid (CSF) is limited when administered intravenously ${ }^{1}$. However, for preeclamptic patients this may not be true as vascular permeability alterations in pre-eclamptic patients may change the transfer of magnesium to the $\mathrm{CSF}^{8}$. There are few studies which suggest increased magnesium passage to CSF in preeclamptic patients ${ }^{9-11}$. Neuraxialanaesthesia is the method of choice in pre-eclampticparturients for 
caesarean delivery,if not contraindicated ${ }^{12}$. Magnesium treatment in severely pre-eclamptic patients may also offer an advantage for anti-nociception following neuraxialanaesthesia. In this prospective observational study, we tested the hypothesis that IV $\mathrm{MgSO}_{4}$ therapy in pre-eclamptic patients would prolong the time to first analgesic request following bupivacaine spinal anaesthesia compared to healthy non-pre-eclampticparturients.

\section{Materials And Methods}

This study was conducted at Indira Gandhi Institute of Medical Sciences, Patna, Bihar, India after taking approval from the Institutional ethics Committee. The duration of study was 1.5 years and was done between September 2014 to March 2016. It was a prospective, observational type of study. Written informed consent were taken from every patient.In our institute all the pre-eclamptic patients are admitted to the obstetric unit after diagnosis and antihypertensive medications along with 24-hour magnesium therapy get started as per the protocol. In patients with gestational age $<34$ weeks, as long as the foetus and the mother are stable, delivery is delayed to achieve foetal lung maturity with conservative treatment. In patients with gestational age $\geq 34$ weeks, delivery is planned after stabilization of the mother. $\mathrm{MgSO}_{4}$ therapy includes a bolus of $4.5 \mathrm{~g} \mathrm{MgSO}_{4}$ given over 10-15 minutes in the labour ward followed by an infusion of $2 \mathrm{~g} / \mathrm{h}$ until transfer to the operating room.

60parturientsof ASA status I-II , Aged 20-50 years, Scheduled to undergo cesearian section and Willing to give written consentwere included in this study who were receiving antenatal care at our institute.Two groups were created- group A \&B. Group A having 30 Healthy parturients were given spinal anaesthesia with $12.5 \mathrm{mg}$ hyperbaric bupivacaine whereas Group Bcontained 30 pre-eclamptic patients who were given spinal anaesthesia with $12.5 \mathrm{mg}$ hyperbaric bupivacaine along with magnesium therapy as per institute protocol described as above. Patients in active labour or in need of emergent caesarean section, contraindication or unwillingness to undergo regional anaesthesia, patients with eclampsia, patients with hemolysis, elevated liver enzymes and low platelets (HELLP syndrome), renal and hepatic involvement of preeclampsia and spinal block failure were excluded from the study.

The clinician collecting intraoperative and postoperative data was blinded to the study. Patient's demographic data (weight, height, age) and gestational weeks were noted and counseled to request for analgesics postoperatively when needed. All patients were preloaded with $500 \mathrm{~mL}$ of lactated Ringer solution in the operating room prior to giving spinal anaesthesia.Lumbar puncture was performed with $25 \mathrm{G}$ Quincke tip needle in the sitting position at L3-4 or L4-5 level using a midline approach. Every parturient were given 12.5 $\mathrm{mg}$ of hyperbaric bupivacaine intrathecally. Patients were then placed $10^{\circ}$ Trendelenburg position with left lateral tilt.

Sensory block was assessed every 30 seconds by using loss of cold sensation to ice at the midclavicular line. Onset of T6 sensory block was defined as the time to loss of cold sensation at the T6 level after intrathecal injection after which the operating table was placed horizontally. Sensory block assessment continued repetitively every 2 minutes, until the block was fixed at the same level on three consecutive assessments. The highest achieved level was defined as the maximum sensory block level. Surgery was allowed to start when pinprick sensation at T6 level was lost. Motor block level was assessed and recorded before surgical incision and at the end of surgery with 10 minute intervals using the modified Bromage scale $(0=$ no motor block with free movement of lower extremities, $1=$ hip flexion blocked, $2=$ hip and knee flexion blocked, $3=$ hip, knee and ankle flexion blocked). Onset of T6 sensory block, maximum sensory block level, motor block level and the time to recovery of motor block were recorded. Time to recovery of motor block was defined as the time interval between intrathecal injection and free movement of the lower extremities. First analgesic request, which was recorded as the primary outcome, was defined as the time period between intrathecal injection and the first occasion when the parturient requested analgesics in the postoperative period. After IV infusion of $1 \mathrm{~g}$ paracetamol, patients were transferred to the labour unit for further observation and treatment.

Non-invasive blood pressure and heart rate (HR) were observed at baseline and at 2 minute intervals following spinal injection for the first 15 minutes and at 5 minute intervals throughout the rest of surgery. Hypotension was defined as a decrease of SBP $>30 \%$ of baseline or $<90 \mathrm{mmHg}$ after spinal injection. Hypotensive episodes were treated with an increased rate of crystalloid infusion. If hypotension persisted in the second consecutive measurement, a bolus of ephedrine $5 \mathrm{mg}$ was administered. Bradycardia was defined as a heart rate $(\mathrm{HR})$ of less than 60 beats per minute $(\mathrm{bpm})$ and was planned to be treated with a $0.5 \mathrm{mg}$ atropine bolus. The number of hypotensive episodes, total amount of fluids administered, median ephedrine consumption and number of patients requiring ephedrine in the operating room until the end of surgery were recorded. The incidence of side effects including shivering, nausea, vomiting and pruritus throughout the study period were noted.

sample size was calculated using lambda willis formula based on data of previous studies. With power of study $80 \%$ and alpha error $5 \%$, the sample size came to 24 . Considering drop outs, 30 patients were recruited in each group. SPSS for Windows 21 (SPSS, Chicago, IL, USA) was used for statistical analysis. Demographic 
data, gestational weeks, magnesium levels, time intervals for spinal anaesthesia characteristics, total amount of fluid administered, blood pressure and heart rate are given as mean $\pm \mathrm{SD}$ and compared with Student's t test. Block level, Bromage score, frequency of hypotensive episodes, ephedrine requirement are presented as median [minimum-maximum] and analysed using Mann-Whitney U test. Chi-square or Fisher's exact tests were utilised for the number of patients requiring ephedrine and intraoperative side effects.P value $<0.05$ was defined as statistical significance.

\section{Results}

Surgical anaesthesia was achieved in all patients without any intraoperative analgesic requirement. Demographic data and gestational weeks were comparable in both the groups (table 1). Duration of surgery were $60.55 \pm 12.82$ mins in Group A and 60.27 \pm 12.84 mins in Group B ( $\mathrm{p}=0.924)$.

Table 1: demographic profile of both the groups

\begin{tabular}{|l|l|l|l|l|}
\hline VARIABLE & GROUP A & GROUP B & P-VALUE & REMARKS \\
\hline Age ( yrs) & $29.2 \pm 5.3$ & $31 \pm 5$ & 0.325 & Non-significant \\
\hline Weight (kgs) & $53.49 \pm 3.35$ & $55.35 \pm 3.61$ & 0.655 & Non-significant \\
\hline Height (cms) age & $152.21 \pm 8.35$ & $149.35 \pm 9.61$ & 0.721 & Non-significant \\
\hline $\begin{array}{l}\text { Gestational } \\
\text { (weeks) }\end{array}$ & $37.2 .2 \pm 1.3$ & $36.9 \pm 1.2$ & 0.425 & Non-significant \\
\hline Duration of surgery & $60.55 \pm 12.82$ & $60.27 \pm 12.84$ & 0.924 & Non-significant \\
\hline
\end{tabular}

Block characteristics are given in table 2. Time to loss of cold sensation at T6 level was significantly faster in the pre-eclamptic group compared to control. Maximum height of sensory block was significantly higher in group B. Onset and duration of motor block were similar in both groups. Time to first analgesic request was statistically longer in Group B compared to Group A ( $p$ value 0.0008 ).

Table 2: Block characteristics of both the groups.

\begin{tabular}{|l|l|l|l|l|}
\hline Variables & Group A & Group B & p-value & Remarks \\
\hline Onset of sensory block & $2.6 \pm 0.42$ & $2.0 \pm 0.84$ & 0.046 & Significant \\
\hline $\begin{array}{l}\text { Maxmht of sensory block } \\
\text { ( T level ) }\end{array}$ & $6.9 \pm 0.48$ & $6.3 \pm 0.74$ & 0.045 & significant \\
\hline Duration of sensory block & $142.6 \pm 8.33$ & $256.6 \pm 7.26$ & 0.0008 & Extremely-significant \\
\hline Onset of motor block & $3.65 \pm 0.43$ & $3.25 \pm 0.54$ & 0.083 & Non-significant \\
\hline Duration of motor block & $109.1 \pm 7.83$ & $121.1 \pm 5.67$ & 0.119 & Non-significant \\
\hline
\end{tabular}

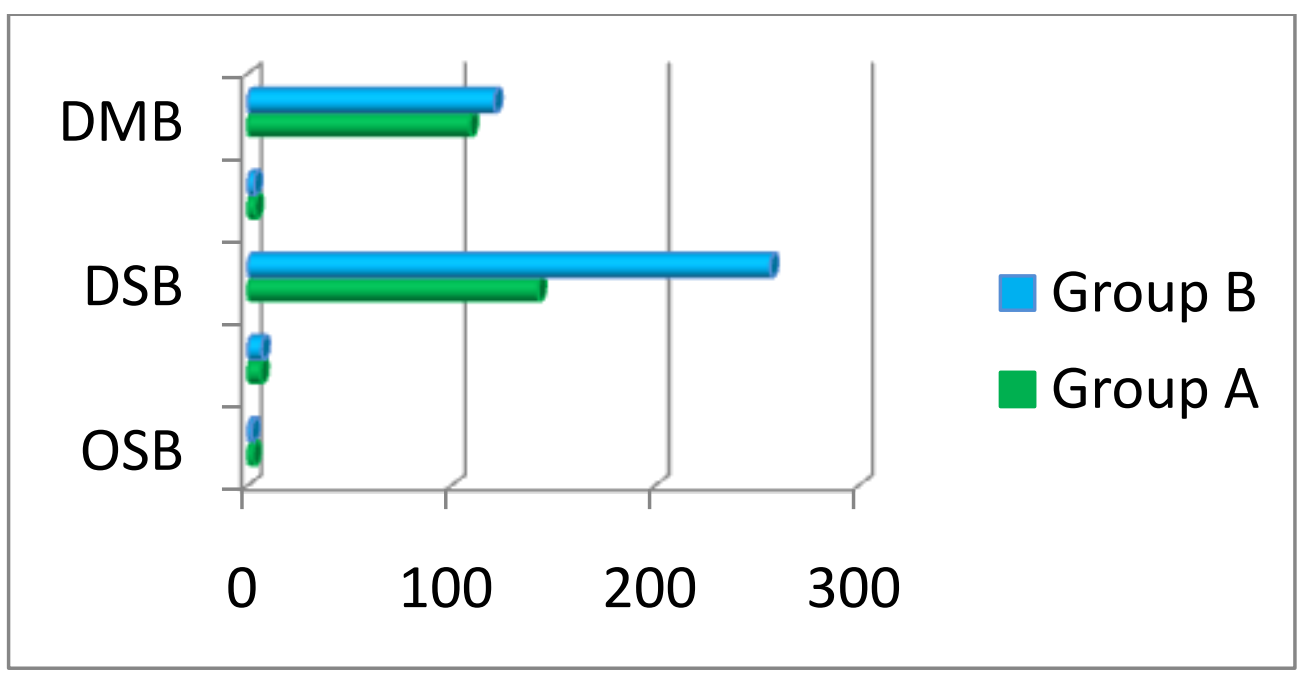

Figure 1: Graphical presentation of block characteristics. 
Baseline, maximum and minimum SBP values were significantly higher in Group B than in Group A. Fluid consumption was higher in Group A, whereas no significant difference was observed in hypotension incidence. Side effects profile was also comparable for both the groups (table 3 ).

Table 4: Side effects profile of both the groups.

\begin{tabular}{|l|l|l|l|}
\hline Side effect & Group A & Group B & P-value \\
\hline Shivering (n) & $5(23.8 \%)$ & $6(30 \%)$ & 0.655 \\
\hline Nausea (n) & $8(38.1 \%)$ & $8(40 \%)$ & 0.901 \\
\hline Vomiting (n) & $2(9.5 \%)$ & $1(5 \%)$ & 1 \\
\hline Pruritus (n) & $7(33.3 \%)$ & $10(50 \%)$ & 0.279 \\
\hline
\end{tabular}

\section{Discussion}

We also observed inthis study that i.v. $\mathrm{MgSO}_{4}$ therapy significantly accelerated the onset of sensory block and also increases the duration and maximum height.

Magnesium is a non-competitive NMDA-antagonist and can potentiate opioid activity with central desensitisation ${ }^{13}$. There are a few studies which have looked at the analgesic effects of IV magnesium in patients undergoing spinal anaesthesia and only few of them have included an obstetric population ${ }^{3-5}$. In all of these studies, lower doses of $\mathrm{MgSO}_{4}$ (ranging from $1.03 \mathrm{~g}$ to $12.35 \mathrm{~g}$ ) were used and the infusions were started after lumbar puncture. In contrast to these studies ${ }^{3-5}$, in our study, pre-eclamptic patients received $\mathrm{MgSO}_{4}$ before spinal anaesthesia and the lowest total dose of magnesium was $28.5 \mathrm{~g}$ in a patient with the shortest infusion duration of 12 hours.

We observed a faster onset of sensory block in Group B than in Group A. Malleeswaranet al. ${ }^{14}$ added magnesium to the intrathecal $10 \mathrm{mg}$ bupivacaine- $25 \mu \mathrm{g}$ fentanyl combination in mild pre-eclamptic patients and reported a slower onset of sensory and motor block following magnesium compared to the control group. Ghrabet al. ${ }^{15}$ observed no differences in onset times of sensory block at the T4 level between the groups with or without intrathecal magnesium. Unlugencet al. ${ }^{16}$ observed a prolongation in sensory block onset by one minute in patients with intrathecal bupivacaine-magnesium combination compared to bupivacaine-fentanyl. None of these obstetric studies explained their findings for sensory block onset and level. Ozalevliet al. ${ }^{17}$ studied the effect of intrathecal magnesium added to isobaric bupivacaine-fentanyl combination in orthopaedic surgery patients and also observed a delay in onset of spinal anaesthesia with magnesium. They speculated that the difference in $\mathrm{pH}$ and baricity of the intrathecal drug combination might have contributed to this delay. The shorter onset time in our study is in contrast to their results, which may depend on the anatomical changes of intrathecal space or composition of CSF due to pre-eclampsia.

We did not observe any difference between the groups with regard to recovery of motor block. Malleeswaranet al. ${ }^{18}$ found prolonged motor block recovery following intrathecal magnesium in mild preeclamptic patients. However, Ozalevliet al. ${ }^{17}$ used the same intrathecal drug combination as Malleeswaran et al. ${ }^{18}$ and reported no difference in motor block recovery.

Sensory block levels achieved in these two studies as well as the patient population may be responsible for their conflicting results. Our results are in accordance with those of Apanet al. ${ }^{3}$, who found a similar duration of motor block but prolonged first analgesic request in their IV magnesium infusion group.

Although not statistically significant, less hypotensive episodes were observed in the pre-eclamptic group, resulting in statistically significant decreased fluid requirements in our study. This was in accordance with Ayaet al. ${ }^{19}$ who also observed a decreased incidence of hypotension in pre-eclamptic patients compared to preterm non pre-eclamptic patients.

The main limitations of the study was small sample size. This study also inherits the limitations of an observational study. The results could be more attributable to magnesium therapy if we would have been done serial serum and csf mg++ analysis. A group of healthy preterm patients receiving the same dose of IV $\mathrm{MgSO}_{4}$ would have given more insight into a relationship between serum/CSF magnesium levels and analgesia duration. However, for ethical reasons, we could not justify such a group of healthy preterm parturients who could suffer possible side effects of preoperative high dose magnesium infusion with no proven benefits. The variable duration and dose of $\mathrm{MgSO}_{4}$ in our study can also be criticised. Due to the nature of the disease, the duration of $\mathrm{MgSO}_{4}$ infusion cannot be standardised in pre-eclamptic patients. Although $24 \mathrm{~h} \mathrm{MgSO}_{4}$ therapy is targeted in pre-eclamptic patients, obstetric progress is individually assessed and the decision for caesarean section could not be forecasted.

\section{Conclusion}

We conclude from this study that Systemic magnesium administration in pre-eclampticparturients prolonged the time to first analgesic request when compared to healthy parturients without magnesium therapy following spinal anaesthesia with bupivacaine. 


\section{References}

[1]. Mebazaa MS, Ouerghi S, Frikha N, Moncer K, Mestiri T, James MF, et al. Is magnesium sulfate by the intrathecal route efficient and safe? Ann FrAnesthReanim. 2011;30:47-50. [PubMed]

[2]. Albrecht E, Kirkham KR, Liu SS, Brull R. Peri-operative intravenous administration of magnesium sulphate and postoperative pain: a meta-analysis. Anaesthesia. 2013;68:79-90. [PubMed]

[3]. Apan A, Buyukkocak U, Ozcan S, Sari E, Basar H. Postoperative magnesium sulphate infusion reduces analgesic requirements in spinal anaesthesia. Eur J Anaesthesiol. 2004;21:766-9. [PubMed]

[4]. Dabbagh A, Elyasi H, Razavi SS, Fathi M, Rajaei S. Intravenous magnesium sulfate for post-operative pain in patients undergoing lower limb orthopedic surgery. ActaAnaesthesiol Scand. 2009;53:1088-91. [PubMed]

[5]. Hwang JY, Na HS, Jeon YT, Ro YJ, Kim CS, Do SH. I.V. infusion of magnesium sulphate during spinal anaesthesia improves postoperative analgesia. Br J Anaesth. 2010;104:89-93. [PubMed]

[6]. Gupta SD, Mitra K, Mukherjee M, Roy S, Sarkar A, Kundu S, et al. Effect of magnesium infusion on thoracic epidural analgesia. Saudi J Anaesth. 2011;5:55-61. [PMC free article] [PubMed]

[7]. Ko SH, Lim HR, Kim DC, Han YJ, Choe H, Song HS. Magnesium sulfate does not reduce postoperative analgesic requirements. Anesthesiology. 2001;95:640-6. [PubMed]

[8]. Amburgey O, Chapman AC, May V, Bernstein IM, Cipolla MJ. Plasma from preeclamptic women increases blood-brain barrier permeability: role of vascular endothelial growth factor signaling. Hypertension. 2010;56:1003-8. [PMC free article] [PubMed]

[9]. Thurnau GR, Kemp DB, Jarvis A. Cerebrospinal fluid levels of magnesium in patients with preeclampsia after treatment with intravenous magnesium sulfate: a preliminary report. Am J Obstet Gynecol. 1987;157:1435-8. [PubMed]

[10]. Fong J, Gurewitsch ED, Volpe L, Wagner WE, Gomillion MC, August P. Baseline serum and cerebrospinal fluid magnesium levels in normal pregnancy and preeclampsia. Obstet Gynecol. 1995;85:444-8. [PubMed]

[11]. Apostol A, Apostol R, Ali E, Choi A, Ehsuni N, Hu B, et al. Cerebral spinal fluid and serum ionized magnesium and calcium levels in preeclamptic women during administration of magnesium sulfate. FertilSteril. 2010;94:276-82. [PubMed]

[12]. Gogarten W. Preeclampsia and anaesthesia. CurrOpinAnaesthesiol. 2009;22:347-51. [PubMed]

[13]. Herroeder S, Schönherr ME, De Hert SG, Hollmann MW. Magnesium--essentials for anesthesiologists. Anesthesiology.2011;114:971-93. [PubMed]

[14]. Malleeswaran S, Panda N, Mathew P, Bagga R. A randomised study of magnesium sulphate as an adjuvant to intrathecal bupivacaine in patients with mild preeclampsia undergoing caesarean section.Int J ObstetAnesth. 2010;19:161-6. [PubMed]

[15]. Ghrab BE, Maatoug M, Kallel N, Khemakhem K, Chaari M, Kolsi K, et al. [Does combination of intrathecal magnesium sulfate and morphine improve postcaesarean section analgesia?] Ann FrAnesthReanim. 2009;28:454-9. [PubMed]

[16]. Unlugenc H, Ozalevli M, Gunduz M, Gunasti S, Urunsak IF, Guler T, et al. Comparison of intrathecal magnesium, fentanyl, or placebo combined with bupivacaine $0.5 \%$ for parturients undergoing elective cesarean delivery. ActaAnaesthesiol Scand. 2009;53:346-53. [PubMed]

[17]. Ozalevli M, Cetin TO, Unlugenc H, Guler T, Isik G. The effect of adding intrathecal magnesium sulphate to bupivacaine-fentanyl spinal anaesthesia.ActaAnaesthesiol Scand. 2005;49:1514-9. [PubMed]

[18]. Malleeswaran S, Panda N, Mathew P, Bagga R. A randomised study of magnesium sulphate as an adjuvant to intrathecal bupivacaine in patients with mild preeclampsia undergoing caesarean section.Int J ObstetAnesth. 2010;19:161-6. [PubMed]

[19]. Aya AGM, Vialles N, Tanoubi I, Mangin R, Ferrer JM, Robert C, et al. Spinal anesthesia-induced hypotension: a risk comparison between patients with severe preeclampsia and healthy women undergoing preterm cesarean delivery. AnesthAnalg. 2005;101:86975. [PubMed] 